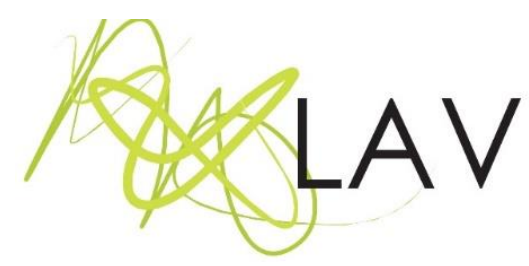

\title{
Visualidades cruzadas. Un caso de indagación sobre las imágenes de la ciencia experimental.
}

Crossed visualities.

A case of inquiry about the images of experimental science.

Fernando Mirandai

Universidad de la República, Uruguay

\begin{abstract}
Resumen
Este artículo aborda algunas cuestiones en torno a la producción de conocimiento en Psicología Básica. Mediante entrevistas y revisión de imágenes se trabaja junto a un grupo de investigadores universitarios a partir de las visualidades producidas en este campo. La intención es conocer cómo el uso de los repertorios de la cultura visual puede abordar los contenidos de las artes, la ciencia y las tecnologías para subvertir la distribución sensible propia de la división disciplinar en que se organiza el conocimiento sistematizado.
\end{abstract}

Palabras clave: visualidades; arte, ciencia y tecnología; distribución sensible

\begin{abstract}
This article involves some questions around the production of knowledge in Basic Psychology. By means of interviews and revision of images we work with a group of university researchers departing from the visualities produced in this field. The aim is to know how the use of the repertories of visual culture can tackle the contents of the arts, science and technologies to subvert the sensible distribution of the disciplinary division in which the systematic knowledge is organized.
\end{abstract}

Keywords: visualities; art, science and technology; sensible distribution

\section{Introducción}

Hace ya algún tiempo que estamos preocupados por cómo los estudios de cultura visual pueden hacerse cargo de los asuntos de las imágenes en contextos de producción científica y tecnológica, fuera de los ámbitos habitualmente autorizados de la cultura, aquellos que son asignados a la experiencia estética.

El problema es que siempre se ha pensado el museo, o la galería, o el espacio expositivo, como los lugares institucionales y físicos en que ocurre el contacto con las imágenes visuales relevantes para un colectivo o una sociedad; cuestión que deberíamos revisar para incluir otros circuitos de experiencia estética.

Revista Digital do LAV - Santa Maria - vol. 11, n. 1, p. 4 - 30 - jan./abr. 2018 ISSN 1983 - 7348 
Pero el asunto, además, no acaba ahí. Es posible indagar qué tipos de conocimientos producen esas imágenes, cómo se relacionan con el conjunto de las prácticas culturales; y cómo, ellas mismas, generan unas narrativas que también tiene un sentido de circulación cultural desde la ciencia y la tecnología.

Nos interesa entonces la producción de imágenes en el sentido en que no hablaremos de artistas acarreando imágenes de las ciencias, sino de científicos produciendo imágenes. Como ha afirmado Jacques Rancière

[I]a cuestión no consiste en aproximar los espacios del arte al no arte y a los excluidos del arte. La cuestión consiste en utilizar la extraterritorialidad misma de esos espacios para descubrir nuevos disensos, nuevas maneras de luchar contra la distribución consensual de competencias, de espacios y de funciones (RANCIÈRE, 2005, p. 71).

Es decir, contra aquello a lo que Rancière ha llamado 'la policía' -para distinguirlo de 'la política'-, no en el sentido de su acepción corriente del aparato represivo ni de de las fuerzas de seguridad del Estado, sino en una observación amplia que define las ubicaciones de los grupos sociales y les comete una acción específica. De manera que

[...] la policía es primeramente un orden de los cuerpos que define las divisiones entre los modos del hacer, los modos del ser y los modos del decir, que hace que tales cuerpos sean asignados por su nombre a tal lugar y a tal tarea; es un orden de lo visible y lo decible que hace que tal actividad sea visible y que tal otra no lo sea, que tal palabra sea entendida como perteneciente al discurso y tal otra al ruido (RANCIÈRE, 1996, pp. 44-45).

De esta forma, las transformaciones de sentido que queramos operar han de pasar por aquella dimensión política favorecedora de la diversidad y la discrepancia, donde su esencia

consiste en perturbar este acuerdo mediante operaciones disensuales, montajes de consignas y acciones que vuelven visible lo que no se veía, muestran como objetos comunes cosas que eran vistas como del dominio privado (RANCIÈRE, 2005, p. 52)

Así, para cualquier intento de transformación que pudiéramos proponer en la búsqueda de disensos -en consonancia con unas posibilidades emancipatorias de 
nuestras prácticas de enseñanza, investigación y divulgación- no podemos ignorar las marcas de época en que los estamos realizando. Quiero decir, toda búsqueda que nos movilice en esta dirección, no puede desplegarse por fuera de lo que plantearemos como las condiciones de lo contemporáneo, en al menos dos sentidos.

Por un lado, nadie parece discutir ya que las prácticas de creación, producción y distribución de aquello que pudiéramos delimitar como lo artístico, - y aún en sus formas de frontera menos reconocibles para lo que cada época definiría como arte se han visto progresivamente modificadas, en distintos sentidos, por los nuevos usos de las tecnologías y por sus relaciones de frontera con la ciencia.

No me refiero exclusivamente a las tecnologías digitales más evidentemente vinculadas a la creación estética y su circulación actual, sino a la apelación a artefactos, dispositivos mecánicos, máquinas y referencias experimentales de las ciencias tradicionales.

Ya son diversas las propuestas de creación contemporáneas que están preocupadas por la relación de aquello que compondría lo artístico con los contenidos, las tecnologías y los saberes del mundo científico. Aún más, en el ámbito institucional de cobijo de los museos o centros culturales conviven, más o menos pacíficamente, formas híbridas sobre las que difícilmente se pudiera decidir si buscan 'estetizar' contenidos científicos, o dar carácter científico a producciones estéticas.

En cualquier caso, y siguiendo a Ingeborg Reichle, podríamos coincidir en que "images from the sciences get involved within a complex interplay between mass media, institutions like science museums and different audiences and new movements" (REICHLE, 2015, p. 74).

Por tanto, si queremos trazar un mapa de posibilidades para la investigación que pueda dar un contenido pedagógico a la relación actual con las imágenes deberíamos incorporar un espacio en que poder expresar estas relaciones a la luz, también, de la experiencia estética y la cultura visual.

Por otro lado, los descubrimientos, teorías y divulgaciones de las últimas dos

Revista Digital do LAV - Santa Maria - vol. 11, n. 1, p. 4 - 30 - jan./abr. 2018 ISSN 1983 - 7348 
décadas, han conducido a las sociedades occidentales a unas formas de representación en que las imágenes - científicas y tecnológicas - van construyendo nuevas maneras de ver e interpretar la naturaleza y el mundo de las relaciones sociales. Para esto, opera tanto la condición del desarrollo de la genética y de la biología molecular; como la construcción imagética del cerebro humano y sus posibilidades y resultados de estudio.

Tal como hacen referencia Giovanni Frazzetto \& Suzanne Anker:

This is hardly surprising as neuroscience carries promises of revealing the underpinnings of our individuality, such as emotions, consciousness, the way we make decisions and our socio-psychological interactions. Advances in brain research, such as the discovery of mirror neurons, thought to be involved in imitation, the recognition of intentions and empathy, the neural correlates of moral choices or the molecules that consolidate or erase memories, strike us as remarkable not only as scientific developments per se, but also for their outreaching societal and cultural repercussions (FRAZZETO \& ANKER, 2009, p. 815)

Para introducir estas preocupaciones en una investigación sistemática, nos preguntamos de manera inicial y abierta: ¿Cómo el trabajo con los repertorios de la cultura visual puede abordar los contenidos de las artes, la ciencia y las tecnologías para subvertir la distribución sensible propia de la división disciplinar en que se organiza el conocimiento sistematizado?

Para esto, a los efectos de este texto, hemos trabajado con un grupo de investigadores universitarios en Psicología Básica ${ }^{1}$, a partir de entrevistas semiestructuradas, realizadas en los propios lugares de desempeño, y con revisión de referencias de imágenes.

Nuestra intención tiene que ver con entender

[...] the process of production knowledge in the sciences. This could only be achieved through collaborations between the sciences and the humanities. The positive results of such an endeavor would be the development of a deeper understanding of the sciences, that science is deeply embedded in culture and that scientific images to a certain

1 Los investigadores participantes en este trabajo pertenecen al Centro de Investigaciones en Psicología Básica (CIBPSI) de la Facultad de Psicología de la Universidad de la República, en Montevideo, Uruguay.

Revista Digital do LAV - Santa Maria - vol. 11, n. 1, p. 4 - 30 - jan./abr. 2018 ISSN 1983 - 7348 
degree mirror current aesthetic concepts and social values (REICHLE, 2015, p. 75).

Finalmente, como modalidad de desarrollo del proceso de trabajo y sus resultados, se realiza una transcripción de puntos de vista y opiniones individuales de los investigadores entrevistados, a partir de su descripción temática, estableciendo su análisis y crítica desde la bibliografía de referencia.

\section{Las imágenes tienen que estar}

Podríamos plantear, como sostiene Reichle (2015) que "the aim of this approach is ultimately to arrive at a picture theory that will facilitate understanding of all kinds of images produced in the sciences (REICHLE, 2015, p. 74).

La pregunta básica para esto tiene, en su aparente sencillez, un reconocimiento evidente hacia la condición visual, y mantiene su vigencia como cuestión en desarrollo, desde que Suzanne Anker la formulara para el Simposio Visual Culture and Bioscience en 2007: "What role do pitcturing practices play in your discipline of 'knowledge' production?" (ANKER, 2008, p. 23).

Para esto, necesitamos indagar qué tipos de imágenes identifican a los miembros de una comunidad científica determinada y qué rol juegan esas imágenes en la construcción del objeto de estudio.

La descripción de contenido de las imágenes, en una disciplina experimental como la que estamos abordando, tiene una relación directa con la modelización del objeto de estudio y su visualización. Así, se afirma, por ejemplo, que

[h]ay mucho cerebritos, eso es seguro. [...] algunas tecnologías que se están usando a nivel mundial que producen imágenes muy lindas, como la Resonancia Magnética Funcional, que son esas imágenes donde se encienden las áreas del cerebro que están activadas cuando se procesan determinadas cosas. [...] Después también vas a ver mucha imagen de ilusión visual, pósteres de ilusiones visuales, que sirven para explicar a gente que incluso venía por otros temas a vernos (Entrevista 1).

O de otro modo:

Al final lo que tenés que encontrar es una manchita en una

Revista Digital do LAV - Santa Maria - vol. 11, n. 1, p. 4 - 30 - jan./abr. 2018 ISSN 1983 - 7348 
serie de cabecitas dibujadas, donde vos mirás, así, y decís si al final anduvo o no. Lo otro es una representación temporal, donde vemos condición uno y condición dos y si hay alguna diferencia, y eso te da si las cosas están funcionando (Entrevista 2).

Ahora bien, lo importante es saber cómo operan esas imágenes en el grupo de pertenencia. ¿Las personas se identifican con las imágenes? ¿Se reconocen por las imágenes que producen?

Vos estás acostumbrado a ver esas imágenes, a trabajar mucho con ellas, entonces las asociás como parte de lo tuyo, de lo que conocés, de hecho hay gente que pone en su perfil de Facebook una imagen de esas [de un experimento]. De manera que es parte de su identidad, es algo que identifica. Son imágenes que representan cosas para vos, la gente pasa muchas horas de su vida tratando de encontrar una imagen que sea buena, que sea representativa de algo que ocurre al nivel del cerebro. Hay una gran búsqueda atrás de esto [...] una imagen de éstas puede ser la imagen central de tu tesis (Entrevista 5).

Las imágenes visuales concentran unos sentidos de identidad, de pertenencia a unos grupos que participan de su reconocimiento. Si una imagen puede constituir un perfil en una red social es porque está asociada a una relación con el hacer cotidiano, con la vida del sujeto, con su lugar en la sociedad, con un núcleo de afinidades; aún en aquel sentido en que lo definía Rancière.

Pero, además, esa imagen que identifica al investigador científico en un lugar social a partir de su trabajo en el laboratorio, colabora en la representación de la condición 'natural' del individuo a nivel social, produciendo una realidad ontológica. Lo que es - lo que existe -, es a partir de la manera en que lo represento. 


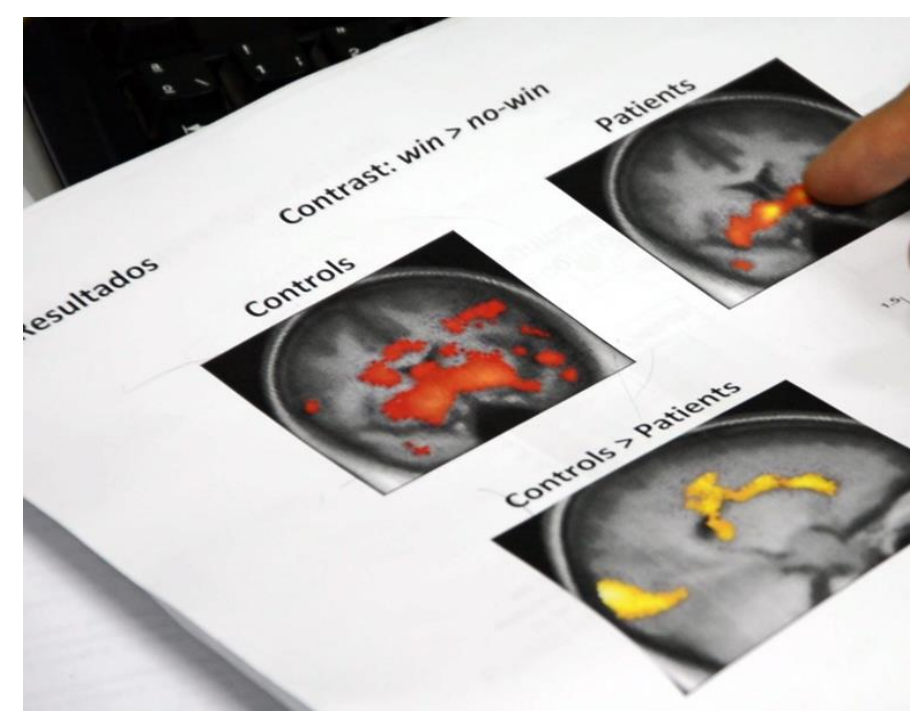

Fig. 01 Imágenes de activación cerebral producidas en condiciones experimentales de contraste de pacientes y grupos de control, a partir de estímulos determinados. (Registro del autor)

De tal forma, la producción visual articula la subjetividad de cada investigador con la producción colectiva de 'lo humano'. En esta línea, de acuerdo al planteo de Reichle, la influencia de la imágenes

upon our understanding of nature remains an issue of social discourse, because these new scientific explanations of the structures and processes of body and mind do, however, challenge our conception and understanding of what we call 'human nature' (REICHLE, 2007, p. 156).

Las respuestas de los investigadores también rondan aquello que nos permitiría conocer qué generan esas imágenes para un grupo científico.

Hay unos repertorios visuales que se crean, se ponen en circulación, se distribuyen en relación con otros investigadores, con participantes de los experimentos y con el público; todo lo cual constituye las visualidades² de esa comunidad.

Desde este punto de vista, la asociación entre belleza y verdad científica es, en muchos casos, directa. De forma que los investigadores asocian elementos de

2 Utilizamos aquí el término visualidades en el sentido de las maneras múltiples y complejas en que las imágenes pueden abordarse, para escapar de un régimen de lo correcto o lo verdadero, y construirse como posibilidades variadas de ver el mundo y estar en él.

Revista Digital do LAV - Santa Maria - vol. 11, n. 1, p. 4 - 30 - jan./abr. 2018 ISSN 1983 - 7348 
descubrimiento, confirmación teórica, o evidencia al concepto estético que elaboran sobre las imágenes visuales que producen.

La producción de estas imágenes, y su calidad asociada tiene que ver, además con la metodología y la realización experimental, pero en cualquier caso, con el hallazgo verdadero. Por ejemplo, en pruebas con activación neural si

las activaciones están donde tienen que estar, están reflejando algo que es coherente, algo que es interesante [...] y esas son las lindas, las que a uno le gustarían. [...] Por ejemplo si vos estás esperando un activación en la amígdala y ves una activación bien clara, entonces decís: 'qué buena imagen' de ese experimento, porque te está mostrando lo que está ocurriendo (Entrevista 5).

Del mismo modo se asume la condición estética en la fiabilidad de los modelos de representación:

Mi trabajo principal, en el que me siento más cómodo es en el de la elaboración de modelos matemáticos y computacionales de procesos vinculados al lenguaje. Ahí aparecen cosas interesantes y que tienen valor estético para mí, hay un valor estético de la matemática en sí misma, de poder condensar en un modelo -quizás simplificado, erróneo, falso- pero que captura alguna de las cosas que queremos ver. $Y$ poder verlo en estructuras que terminan siendo espaciales, como una red de conceptos, o cómo se vinculan con la red de neuronas, o como puedo escribir eso en un conjunto de ecuaciones que también tienen su plasticidad, eso es lo que me mueve (Entrevista 2)

Estas visualidades propias del espacio científico, constituyen modelos de representación que, al mismo tiempo, construyen una idea de verdad y asocian a esta una condición estética de belleza, en su definición más difundida.

Lo interesante es ver cuál es la relevancia de algunas de esas imágenes y respecto a qué éstas se vuelven relevantes. ¿Cómo podríamos categorizarlas?

Por ejemplo, si es una imagen que me está mostrando una diferencia significativa entre pacientes y controles, tal vez sea la imagen que me guste. Porque es como que me está diciendo algo, me está dando información acerca de algo que está ocurriendo en el cerebro de los pacientes. También imágenes que son muy definidas, muy claras, con poco ruido... (Entrevista 5 ).

Revista Digital do LAV - Santa Maria - vol. 11, n. 1, p. 4 - 30 - jan./abr. 2018 ISSN 1983 - 7348 
Aunque pudiéramos asumir que ambas ideas - verdad y belleza - son coyunturales y están delimitadas por contextos históricos, tanto en la ciencia como en el arte, lo cierto es que parecen completar un binomio directamente asociado a la actividad científica y a sus visualidades.

Al mismo tiempo, parece que tal dupla conceptual acaba por operar firmemente en el diseño del mundo real o de la naturaleza humana a partir de su producción como evidencia científica que no sólo explica el mundo, sino que, principalmente, lo construye.

\section{La producción de visualidades en investigación experimental}

Como investigadores en el campo de los Estudios Visuales estamos motivados por conocer qué sucede con las visualidades surgidas de las situaciones experimentales, y cómo están informadas y construidas más allá de los entrenamientos específicos de sus productores y sus participantes.

En estas situaciones de laboratorio acontecen posibilidades de producción que trascienden el marco de la investigación y permitirían abrir espacios híbridos de colaboración en el sentido en que lo refiere Anker

[...] one may inquiry, what migratory attractions between these disciplines are currently present? One aspect of art's relationship to science is evident within modes, styles, and devices of visual representation (ANKER, 2008, p. 22).

Si seguimos, por ejemplo, las condiciones experimentales de los estudios del movimiento, y sus resultados, podemos obtener las pistas para ampliar los marcos de relación entre arte y ciencia, a partir de las visualidades.

En el siguiente testimonio podemos tener las primeras aproximaciones respecto de lo que queremos probar:

Se dedican muchas horas, tanto con los objetos como con las manos. Para una imagen de agarre se precisan diez fotos, hay que trabajarlas todas una por una, es un elemento familiar, seguramente hay toda una relación afectiva con todo eso que vas haciendo, como con cualquier cosa que uno hace. Con los participantes la relación es breve, de cinco o diez minutos que ve las imágenes, donde la gente se extraña

Revista Digital do LAV - Santa Maria - vol. 11, n. 1, p. 4 - 30 - jan./abr. 2018 ISSN 1983 - 7348 
un poco porque viene sin saber lo que va a ocurrir. Pero creo que son lindas las imágenes, que lucen bien (Entrevista 3)

Estos estudios de movimiento son, a mi juicio, un entorno posible para mostrar las condiciones potenciales de la colaboración entre arte y ciencia - y del desarrollo de la experiencia estética en espacios experimentales de la ciencia -, pero sólo si tenemos la apertura de trascender las fronteras impuestas por la división disciplinar referida al comienzo.

Los alcances y consecuencias del estudio del movimiento han sido tanto preocupación de la ciencia como del arte, y la producción visual en torno a estas indagaciones plantea desafíos de colaboración posible.

Lo corporal (y con ello lo cinestésico y lo sensorial) constituye oportunidades de sentido para que cada productor o usuario de las visualidades, que explican o representan estos fenómenos, establezca su conjunto particular de referencias.

Es Charles Garoian (2013) quien por ejemplo referencia la idea del arte 'en carne y hueso' (art-in-the-flesh) y establece una evidencia de la condición corporal del arte. Lo hace tanto en una experiencia de transformación de la materia llevada a cabo por una de sus alumnas, como en la condición corporal de la lectura de un libro a partir de las intervenciones y sensaciones que evidencian el diálogo con el texto.

Para Garoian esto constituye una doble condición donde se juega el cuerpo como espacio de producción y relación con lo artístico cuanto la percepción del mundo a través de esta corporalidad, lo que provoca simultáneamente la agitación de los sentidos como del pensamiento. El cuerpo es entonces una posibilidad, una herramienta, cuanto un artefacto cultural para incidir en el mundo que nos rodea.

En la condición experimental - y en sus visualidades - podemos encontrar la idea de lo corporal con relación a situaciones de continuidad y discontinuidad, pues estos movimientos tienen esta doble cualidad; al mismo tiempo que los cuerpos que los producen cargan con una colección de afectos, movimientos y hábitos.

Revista Digital do LAV - Santa Maria - vol. 11, n. 1, p. 4 - 30 - jan./abr. 2018 ISSN 1983 - 7348 




Fig. 02 Imágenes de estudio de movimiento cedidas por el equipo de investigación del CIPBSI

Por esto, podemos coincidir en la opinión con Anker en tanto

[w]hether conscious or not, these crossovers in visual application, narrative interpretation, and symbolic models of the real continue to exude and reframe the philosophical implications of perception and cognition, authenticity and artifice, in both science and art (ANKER, 2008, p. 22).

Así, deberíamos asumir estas experiencias en su posibilidad de transgredir los límites establecidos en la división de lo sensible, y las formas en que podrían enriquecer la vida común de las personas. Si, como hemos visto, esto no es novedoso en cuanto análisis y antecedentes en que los artistas se han movido a los laboratorios, lo sería más si sacáramos las prácticas de los laboratorios en su capacidad de generar nuevas experiencias visuales a partir de condiciones experimentales.

En nuestro propio análisis de la experiencia de movimiento existen relaciones con formas visuales y prácticas de producción artística que han constituido, y constituyen, posibilidades de transgresión de límites sensibles.

Una experiencia como la consignada tiene el potencial de hacer emerger nuevas conexiones. ¿No podríamos pensar estas visualidades para describir e interpretar situaciones históricas? ¿No deberíamos usar estas visualidades para generar 
colaboraciones con lo que habitualmente definimos como el campo artístico? Utilizaremos para esto un par de ejemplos breves, que referencian lo que queremos establecer. En el primer caso, es el propio Garoian, ya citado, quien junto a Yvonne Gaudelius (2008) analiza los patrones ornamentales de movimientos que ofrecían los espectáculos de masas - por ejemplo las Tiller Girls -, imitando e igualando el movimiento de las manos de los obreros de las fábricas de comienzos del siglo XX.

En el segundo caso, es Alexander Schwan (2013) quien analiza las secuencias de los movimientos de la danza contemporánea como verdaderas caligrafías corporales en el espacio, condición que perfectamente podríamos asociar a los experimentos sobre el movimiento si quisiéramos ampliar sus límites y colaboraciones.

Estas ideas, sin embargo, no están alejadas de intuiciones de los propios investigadores respecto a las posibilidades y conexiones de su campo experimental con otras disciplinas científicas, las que podrían ampliarse a espacios de lo artístico y de lo cotidiano.

De este modo, se afirma:

La gente que viene más de la formación humanística tiene grandes dificultades de comprender este lenguaje visual, entonces pensamos que era un déficit en la formación en matemáticas [...]. Pero me he dado cuenta que los estudiantes deberían jugar más a la 'batalla naval', porque en el fondo, cuando estás ubicando un punto en una gráfica, es como jugar a la batalla naval, con dos coordenadas -o en el espacio con tres coordenadas-. Esa idea cuesta mucho cognitivamente, no sé si porque no se jugó suficiente a la batalla naval $[\ldots]$ y queda como una fórmula absurda, que no tiene ninguna representación con la vida real y que es algo tan importante para entender el mundo. Hay que intentar análisis matemáticos de cosas que respondan a la realidad, que no sean absurdas... (Entrevista 1)

Si esto fuera así, deberíamos anotar con énfasis la importancia de la producción y la negociación de las imágenes. No son, aunque lo pretendan o parezcan, una descripción fiel de la naturaleza; sino que establecen una forma de concebir la naturaleza de un modo representacional. Esto, que hemos esbozado hasta aquí, es lo que consideraremos en el siguiente apartado.

\section{(Re) Presentado el mundo}

Revista Digital do LAV - Santa Maria - vol. 11, n. 1, p. 4 - 30 - jan./abr. 2018 ISSN 1983 - 7348 
Lo que sigue tiene que ver con establecer las particularidades de la producción de imágenes experimentales de la ciencia y sus consecuencias. ¿La imagen funciona como representación del mundo? ¿O será que la imagen produce el mundo?

En cualquier caso, esta representación se ha ido transformando con los estudios del cerebro $y$ "as part of this transformation, ideas, images and concepts of neuroscience are increasingly assimilated into the cultural imagenary" (FRAZETTO \& ANKER, 2009, p. 815).

A esto tampoco es ajeno las representaciones artísticas del quehacer científico. Suzanne Anker se refiere a este concepto incluso para su propio trabajo donde las imágenes juegan un doble rol:

They are a thinking apparatus by which models of the symbolic can be externally visualized. By their existence, these models move into culture and generate, on their own terms, alternate ideas, solutions, concerns, and further representations (ANKER, 2008, p. 51).

Así también las representaciones artísticas del quehacer científico se involucran y se establecen como posibilidades de significado para los investigadores de la ciencia.

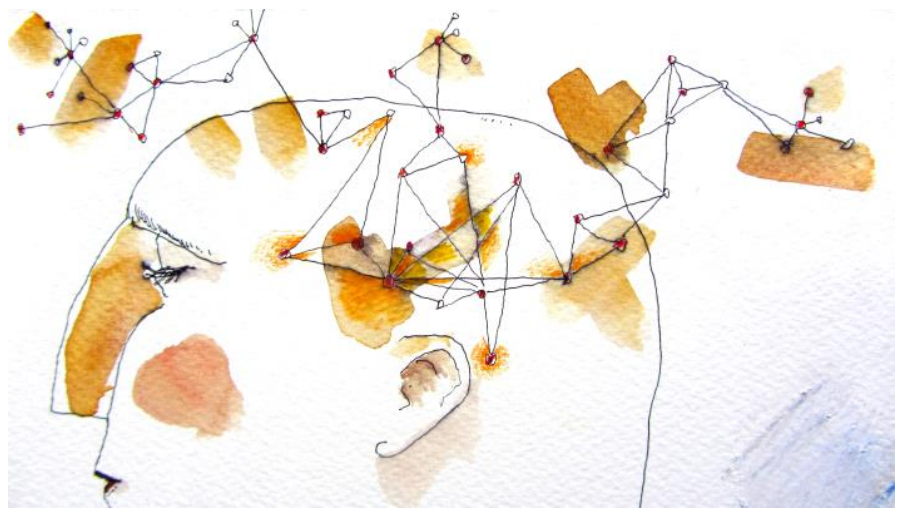

Fig. 03 Detalle de obra de Fulvio Capurso representando la actividad experimental de los investigadores del CIBPSI

Hay una condición de identidad de los investigadores en esa producción de imágenes, tal como hemos referenciado antes en este trabajo, pero que al mismo tiempo convive con la fantasía de que puede existir un lejano o inexistente 
reconocimiento del productor. Es decir, que debe perseguirse la creación de unos repertorios de imágenes neutrales que no identifiquen la condición de autor. Esta condición ideal se expresa así:

\begin{abstract}
La tendencia es a que todo sea muy neutro, como cosas prototípicas donde no se atribuyan otras cuestiones -si el martillo es más antiguo o más moderno- se busca lo estándar, una tendencia a lo neutro que hace que no haya cosas de identidad del investigador. Las investigaciones se suelen replicar, se utilizan estímulos que se han usado en otros trabajos, porque se han encontrado obstáculos 0 resuelto situaciones, entonces se utiliza el mismo gesto que otra persona que comprobó un cierto efecto (Entrevista 3)
\end{abstract}

Sin embargo, esta búsqueda que intenta evitar el reconocimiento autoral contrasta con la necesidad de producir un espacio creativo. Esto, de alguna forma, genera una suerte de tensión entre la necesidad de la evidencia experimental - y su representación visual - y el reconocimiento de aquel espacio de gesto reconocible.

Lo que pasa es que yo no sé si mucha gente se da cuenta de esta parte, como que no se tiene tan en cuenta, y eso se ve mucho en las presentaciones en conferencias o en pósteres de congresos. Cosas muy buenas pero que no tienen ninguna sensibilidad estética. En un póster algo muy importante es la estética, la presentación, menos texto y más imágenes, pero no toda la gente lo tiene en cuenta (Entrevista 4)

De todas formas, la necesidad de la expresión visual del resultado experimental es inevitable, hasta para el reconocimiento de afinidades disciplinares en la búsqueda de resultados similares, o de contraste de resultados propios. Esto tiene, además, consecuencias en la construcción de la identidad articulada en la participación en la masa crítica de la disciplina: las imágenes visuales permiten la búsqueda de un otro igual a mí.

Cuando vos ves otras personas dedicadas a lo mismo, que para mí es algo muy interesante, obviamente hay una identificación. Si estoy buscando en revistas especializadas y veo una fotografía te diría que llama la atención, que te das cuenta de qué va el tema (Entrevista 3).

Esta construcción disciplinar, y el consecuente resultado de reconocimiento de afinidades personales y temáticas es parte constitutiva de las disciplinas $y$, seguramente, refuerza la condición de la división de las sensibilidades en el sentido

Revista Digital do LAV - Santa Maria - vol. 11, n. 1, p. 4 - 30 - jan./abr. 2018 ISSN 1983 - 7348 
de la policía tal como lo hemos referenciado de Rancière en este mismo texto.

Con esto quiero significar que los investigadores buscan a sus pares también a partir de las imágenes visuales de los resultados científicos que obtienen y éstas constituyen una representación de logros, pero también unos repertorios de reconocimiento posible de una determinada comunidad académica.

Estos repertorios están lejos de ser neutros o carentes de subjetividad, aunque esa sea la ilusión presente muchas veces. Por el contrario vehiculizan modos de hacer, de representar, y de acción que son propios y regulados como señal de pertenencia y aceptación; modos que restituyen cada vez las condiciones esperadas de actuación para tal o cual posición preestablecida en el campo científico.

Las visualidades propias de un campo científico participan en unas tensiones que, al tiempo que aparentan continuidad y homogeneidad, refieren a las contingencias históricas -disciplinares, sociales, económicas- de lo que en cada momento se espera que sea la investigación, los investigadores, y las imágenes aceptadas.

Algunos investigadores lo expresan claramente:

[...] hay otro ámbito que es el de las comunicaciones científicas, cuando vos hiciste el experimento, analizaste, produjiste un texto explicando lo que estuviste trabajando, e incluís las imágenes para una masa crítica de gente que trabaja en esa línea. No es demasiada gente porque, como en cualquier área muy especializada, no hay una comunidad muy extensa pero es bastante gente que, al ver esa mano en movimiento, la aprecia, le presta una atención muy distinta y peculiar. Estás en otros lados, en Inglaterra por ejemplo, y ves gente que se dedica a lo mismo, un montón de personas que ves recortando manos con Photoshop, y causa gracia, es un grupo de gente que ve esto de otra manera (Entrevista 3).

Como ejemplo, este testimonio expresa de forma evidente lo que venimos analizando. Pero, al mismo tiempo, la posibilidad descriptiva de las acciones que se realizan en el espacio científico específico es también la aceptación de que las cosas son de un modo...pero podrían ser de otro.

Esta oportunidad introduciría la política como posibilidad de transformar las reglas

Revista Digital do LAV - Santa Maria - vol. 11, n. 1, p. 4 - 30 - jan./abr. 2018 ISSN 1983 - 7348 
de juego del espacio académico regulado por la división disciplinar, lo que siempre necesita de un reconocimiento de la condición histórica del conocimiento. En términos de Ingeborg Reichle:

\begin{abstract}
Visualizations from the field of the natural sciences are never simply illustrations, but instead represent complex phenomena, which in their formulation are always bound by the conventions of representation and the reigning vocabulary style of their respective period or time. They touch upon arrangements as to the ways in which respective scientific context captures knowledge in an image and ascribes to it an epistemological meaning. Visualizations and models are without question significantly involved in the formation of knowledge and have always been an integral component of scientific efforts and legitimate heuristic means of forming theories (REICHLE, 2007, p. 159).
\end{abstract}

Aún así, los repertorios visuales producidos involucran condiciones creativas de los investigadores que apelan a características personales difícilmente regulables por la estructura del campo disciplinar. Tales características parecen más propias de posibilidades e improntas personales que de formas de acción aprendidas, y su desarrollo tendría que ver más con un estilo individual que con una formación que pudiera generalizarse.

De este modo, alguno de los colaboradores de este trabajo compara la demostración científica con un caso de prueba judicial. La descripción es interesante porque alcanza una manera de divulgación del método próxima a la cultura popular y fácilmente accesible más allá de la pertenencia al campo científico.

Se afirma, entonces, que

Hay que mostrar el quiebre con algún caso muy notorio, vas al choque. Tenés que decir: 'Si esto fuera así, tendría que pasar esto. No pasa esto'. El ejemplo es porque no se puede en una charla científica demostrar nada, en el sentido matemático del término, ni dar todos los fundamentos. [...] Tenés que mostrar con un ejemplo, tenés que armar el caso. Sos como un fiscal que tiene que armar el caso y decir que hay un crimen... a gente que no está convencida ni de que hay un crimen (Entrevista 2).

Estas condiciones personales se combinan con la localización geográfica de los

Revista Digital do LAV - Santa Maria - vol. 11, n. 1, p. 4 - 30 - jan./abr. 2018 ISSN 1983 - 7348 
investigadores y los accesos a la divulgación de sus resultados experimentales. Si la función de policía dirime las características de la división disciplinar de lo sensible, también opera dentro de cada campo.

Es de esta forma que las segmentaciones y jerarquías disciplinares operan en la producción y distribución de los resultados científicos y, en consecuencia también, de las visualidades. Si estableciéramos características geo-científicas de los desarrollos y reconocimientos disciplinares, veríamos claramente operar estas posibilidades de acceso y distribución, donde las oportunidades de llevar "el caso" adelante, están regidas por una estructura de desigualdades.

Este reconocimiento es claro desde lo testimonial:

También hay una cuestión muy importante de centro y periferia. [...] vos no estás en el centro de la disciplina, como en el Departamento de Policía de Nueva York; estás en la comisaría de Calamuchita, con el que robó una bicicleta. Pero sí que capaz que el que robó la bicicleta es un asesino. Entonces, sucede que vos no tenés toda la película, tenés imágenes, partes desde las que tenés que armar. Es como la novela policial; tenés que armar el caso con un conjunto discreto de pistas (Entrevista 2).

Las imágenes visuales que representan el mundo y constituyen las evidencias del caso tienen que ver con gráficas, esquemas, fotografías, u otras surgidas de - o soportadas en -, las tecnologías en uso. Pero son estas imágenes las que constituyen las visualidades de un campo disciplinar, dan sentido al mismo, y organizan sus condiciones conceptuales, sensibles, afectivas, y estéticas.

Siguiendo en la línea de Reichle, coincidiríamos a partir de los testimonios de nuestros colaboradores de investigación, que las representaciones gráficas

do not directly depict measured data, but rather are translated or converted into other media and visualized in diverse presentational forms that can be expressed using various representational conventions: in the form of curves, diagrams, or complex image rasters or other symbolic representations (REICHLE, 2007, p. 160)

Revista Digital do LAV - Santa Maria - vol. 11, n. 1, p. 4 - 30 - jan./abr. 2018 ISSN 1983 - 7348 

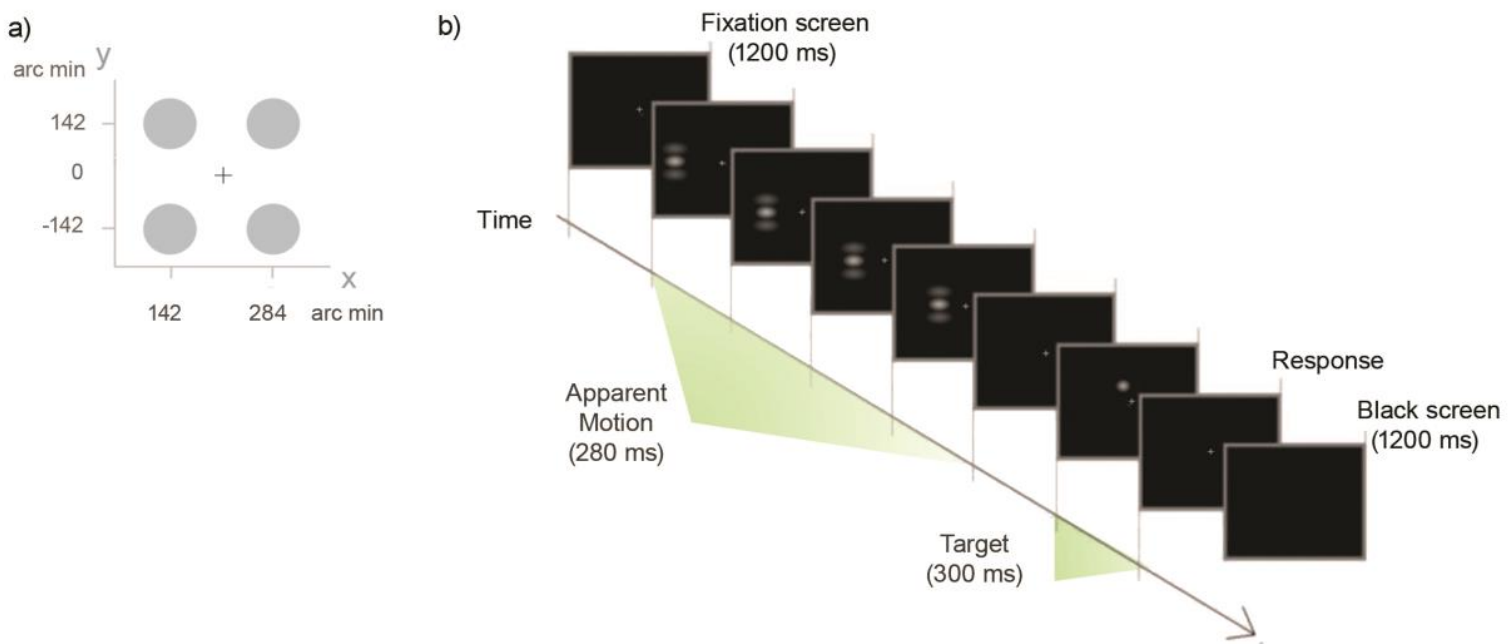

Fig. 04 Imágenes de resultados de estudios de percepción cedidas por el equipo de investigación del CIPBSI

Estas representaciones amplían el espectro de muestra de los resultados y los hacen accesibles, en primera instancia, a los pares de la academia. De tal manera que cuando el investigador realiza una gráfica

[...] lo que estás tratando de hacer es ponerte del lado de la posición del lector, que obviamente no tiene toda la información que vos tenés, que viene con una información que vos ya le diste en el texto escrito y que le tenés que condensar en una imagen lo más importante o lo más impactante. Entonces hay mucho de didáctica metido ahí pero como arte más que como técnica (Entrevista 1 ).

La condición artística mencionada retoma el tema del lugar de la experiencia estética, más que por el sentido moderno de la idea de belleza, por la producción de un condensado visual en que se producen una serie de consecuencias que modifican ideas, movilizan afectos, y producen sensaciones, para explicar determinados fenómenos.

En el ochenta por ciento de las veces no encontraste nada, ahí lo que tenés es frustración. [...] Pero hay momentos en que las cosas caen como vos querés y te emociona hasta las lágrimas y poder decir: 'está acá, lo que estoy buscando está ahí' (Entrevista 2)

Y cuando se ven el tipo de representaciones visuales que implican el alcance de

Revista Digital do LAV - Santa Maria - vol. 11, n. 1, p. 4 - 30 - jan./abr. 2018 ISSN 1983 - 7348 
logros, estos también son posibles de ser pensado más allá de las fronteras de lo científico en su división sensible. Y hubiera que elegir una imagen que representara el trabajo, la disciplina científica, la que identificara el libro que se fuera a escribir.

Quizás [sería] un juego de miradas al estilo Rembrandt, no es mi disciplina, pero creo que representaría mi trabajo. [...] Lo que suele pasar es que las imágenes están asociadas a una cantidad de momentos de esfuerzos, de frustraciones porque también está lleno de frustraciones-, o momentos de éxito, o de cosas que lograste, entonces tenés un componente afectivo. Entonces [es] cuando te chocás con una imagen a la que estuviste dedicando mucho, y se transformó en un paper o en un poster, ...es difícil encontrar una, pero básicamente para mí lo que son las imágenes de los gestos de mano [...] son una historia personal (Entrevista 3).

A partir de aquí, el siguiente momento nos conducirá a las ampliaciones posibles de los límites disciplinares por la apertura de espacios colaborativos.

\section{Las visualidades cruzando los límites de la ciencia y el arte}

Una posibilidad especial de las ciencias experimentales que involucran respuestas de sujetos humanos es la participación de personas no iniciadas en el campo científico ni en la investigación.

Las imágenes científicas no tienen -no podrían tener- solamente un motivo vinculado a la propia disciplina. También deben operar las posibilidades de la divulgación; de saberes que esas imágenes pueden mostrar a otros no expertos, a gente que no tiene explicación de lo que hay por detrás de una imagen.

Qué pasa con los pacientes o su entorno; qué pasa con adolescentes que puedan interesarse en la disciplina; qué pasa con los participantes de los experimentos y pruebas...

Estas personas se convierten, de hecho, en un primer círculo de proximidad y de difusión del quehacer científico hacia los espacios cotidianos, negociando otras representaciones de la ciencia que circulan por fuera de los laboratorios y de la academia.

Revista Digital do LAV - Santa Maria - vol. 11, n. 1, p. 4 - 30 - jan./abr. 2018 ISSN 1983 - 7348 
Pero para que esta atracción de sujetos hacia la experimentación ocurra, para que las personas acepten someterse a ciertas condiciones regladas de la investigación, debe estar sucediendo una circulación de significados acerca de lo que la ciencia es, y en particular determinadas ramas de esto.

En tal sentido, las apelaciones a la actividad cerebral - y sus representaciones -; a la interrelación entre las personas - y un carácter protagónico de participación -; así como una atracción por lo que en definitiva se desconoce - y una forma de misterio - parecen ser, para algunos investigadores, los ejes que estructuran la participación de los colaboradores.

Ante la pregunta de cuáles son las imágenes para convocar a la disciplina de investigación, para seducir sobre la importancia de un área experimental, las respuestas son variadas. Sin embargo, los ejes referidos parecen mantenerse.

Hay investigadores que consideran que la atracción podría darse por la utilización de

personas interactuando $[\ldots]$ en Psicología volcada a la cognición siempre se usa la imagen del cerebro, eso atrae a la gente que le interesa todo lo que tiene que ver con lo 'neuro'; pero yo utilizaría la interacción entre personas, una escena que fuera atractiva... (Entrevista 3).

Otros apelan a la seducción de la idea de la centralidad de la actividad cerebral y su construcción de las subjetividades al tiempo que de la condición de la propia especie humana.

Trabajo por ejemplo en como el cerebro procesa estímulos de movimiento, la teoría en que me baso tiene que ver con la pre-activación neuronal. [Lo que pasa que no estamos en una actitud meta-consciente de la percepción, sino todo lo contrario, entonces] me gusta mucho esta dicotomía entre lo que pasa en el cerebro y lo que vemos. [...] Las emociones básicas pasan en todas las culturas, el miedo, la alegría, el asco, la tristeza y la sorpresa son iguales. Tanto la expresión que hacemos, como los músculos que se mueven, como la identificación de la emoción es algo básico. [...] En eso no hay diferencia cultural, luego sí, como habla, como se expresa va a ser diferente según la cultura, pero el nivel básico es igual. [...] A mí me importa mucho eso, como procesamos las cosas a nivel básico, sin entrar la cultura. [...] Me gusta pensar que nunca voy a tener las respuestas,

Revista Digital do LAV - Santa Maria - vol. 11, n. 1, p. 4 - 30 - jan./abr. 2018 ISSN 1983 - 7348 


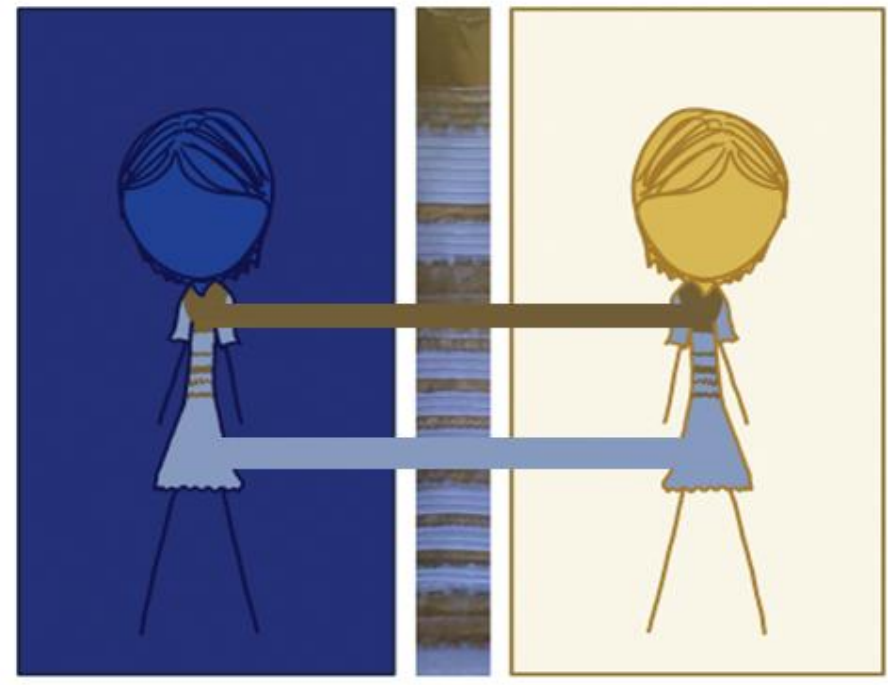

Fig. 05 Imágenes de estudios de ilusión óptica, elaboradas por Fulvio Capurso, cedidas por el equipo de investigación del CIPBSI

Al final, es posible que los participantes nunca conozcan los resultados que ayudan a construir en la colaboración científica ya que lo que sucede "es que son experimentos que a veces son aburridos o demoran mucho tiempo, porque la gente tiene que identificar si algo sube o baja, o si aparece algo, no son fáciles y tienen que estar concentrados..." (Entrevista 4).

Sin embargo, las personas participan sobre la convicción de que esto es también parte del misterio de lo experimental. Frazzetto y Anker citando al escritor Jonah Lehrer referencian mencionan también este extremo en que "as 'science needs art to frame the mystery, but art needs science so that not everything is a mystery'." (FRAZETTO \& ANKER, 2009, p. 820)

Es también Jacques Rancière quien menciona la condición del misterio en la producción contemporánea, su potencialidad para unir heterogeneidades.

Dirá Rancière que

el misterio pone el acento sobre el parentesco de los heterogéneos. Construye un juego de analogías por el que estos ponen de manifiesto un mundo común en el que las

Revista Digital do LAV - Santa Maria - vol. 11, n. 1, p. 4 - 30 - jan./abr. 2018 ISSN 1983 - 7348 
realidades más alejadas aparecen como talladas en el mismo tejido sensible y pueden unirse siempre por la fraternidad de una metáfora (RANCIĖRE, 2005, p. 47).

Es quizás este misterio, el que constituya una de las alternativas estratégicas de la producción cultural - científica, tecnológica, o artística - para animarse a cruzar fronteras. Para hacer política de esta posibilidad de romper la división disciplinar de lo sensible.

\section{El lugar de las imágenes en la división disciplinar}

En el apartado anterior, derivamos en que la división disciplinar también produce una división sensible respecto de la relación con las imágenes visuales. Esto parece especialmente evidente en el sistema académico donde, en muchos casos, los jóvenes eligen prontamente una orientación de formación.

Las opciones afirmativas tempranas -en favor de un interés disciplinar de estudio e investigación- también dejan por el camino, o definitivamente niegan, otras posibilidades. $Y$ en esa afirmación -y su contracara de negación- se produce un refuerzo de la división señalada.

Esto genera, muchas veces, ciertos prejuicios acerca de que las personas que se dedican a las ciencias o a las tecnologías en diferentes campos se alejan de las humanidades en general y, en particular, de las artes.

Si esto no fuera así, no existiría la preocupación manifiesta de acerca de las condiciones de las visualidades en sus proximidades a lo científico o a lo artístico, y el creciente interés de los artistas contemporáneos por ensayos de colaboración con el mundo de la ciencia y dentro de los laboratorios. ${ }^{3}$

Es para nosotros evidente que la aproximación y lugar de las imágenes visuales cumple en muchos casos las mismas condiciones que asumiríamos para las producciones artísticas y habitualmente negamos para las ciencias. Especialmente en cuestiones afectivas, sensibles, y estéticas, tal como hemos referido antes. Las atracciones de los resultados -y las visualidades asociadas- movilizan y afectan a los investigadores, hasta contrariar asunciones propias de un determinado régimen

3 Para esto es interesante volver sobre el debate surgido del Simposio sobre Cultura Visual y BioCiencia, coordinado por Suzanne Anker (2008) y referido en este texto.

Revista Digital do LAV - Santa Maria - vol. 11, n. 1, p. 4 - 30 - jan./abr. 2018 ISSN 1983 - 7348 
disciplinar.

Así, por ejemplo, funcionan búsquedas que tienen que ver con que,

[I]as explicaciones en la Biología siempre requieren de la variedad, para mi el concepto de variedad es atractivo, aunque sea ruido, porque el ruido también tiene patrones que a veces están ocultos. [...] Una cosa que me atrae siempre es hacer aparecer el orden detrás del caos numérico (Entrevista 2).

Y al mismo tiempo:

Yo no espero que el mundo sea regular, ni a nivel social, ni psicológico, ni tampoco a nivel biológico. La Biología tiene que incorporar, de hecho incorpora en sí misma la variación como componente esencial. No hay evolución si no hay variación. Lo que vamos a poder decir son cosas como: 'esto está armado así y funciona así'. Ahora, hay lugar para eventos inesperados, que no sabemos cuales son (Entrevista 2)

De otro modo también,

[I]o que es cierto es que en la ciencia los resultados positivos siempre generan más atracción que los negativos [...] para mí se tendrían que publicar mucho más los resultados negativos, porque también aportan a otros científicos (Entrevista 5).

Las condiciones de seducción y afectación sensible a partir, por ejemplo, de los temas de variedad/ruido, caos/orden, éxito/fracaso, regularidad/sorpresa se transforman más que en pares dicotómicos, en valores que puede también sentar las bases de una alteración política de las actuales delimitaciones de la ciencia y el arte.

De hecho, estos temas son parte de la agenda de muchas de las producciones artísticas contemporáneas -ya lo hemos indicado para la idea de misterio- y podrían dotar de sentido a mayores interacciones por una ruptura de una división disciplinar que se transforma - la mayoría de las veces y en la práctica - en una realidad excluyente.

Revista Digital do LAV - Santa Maria - vol. 11, n. 1, p. 4 - 30 - jan./abr. 2018 ISSN 1983 - 7348 
Los investigadores científicos perciben claramente esta necesidad en el movimiento hacia las artes u otras disciplinas, para el caso, una de nuestras colaboradoras dirá lo siguiente:

Creo que la gente tiene que saber que las cosas que vemos se construyen en la corteza visual, que las cosas que vemos son una ilusión, que nuestro cerebro construye todo lo que vemos. Esto es muy importante porque vivimos pensando en que las cosas que vemos son como las vemos y como las tocamos y no es así. [...] Esto es algo que tendría que estar en Psicología, en Artes, en Arquitectura, en Biología,... ay que tener una construcción más global (Entrevista 4)

Por eso, estas posibilidades parecen concordantes con la idea de que "scientific imagery has become as socially, ethically, and aesthetically challenging as the production of aesthetic images" (REICHLE, 2015, p. 75)

No estamos hablando de una dimensión artística de lo disciplinar, no es una cuestión de museificar una imagen científica, sino de las consecuencias de las imágenes en sus contextos de producción para los investigadores y académicos, tanto como para la construcción cotidiana de la ciencia a nivel popular.

En distintos trabajos la misma autora (REICHLE, 2003; 2007) llega a este punto cuando, por ejemplo, afirma que con la ayuda de la "iconography of images from science, the attempt is made to decipher the cultural codes that these images transport additionally" (REICHLE, 2003, p. 1)

De este modo, uno de nuestros colaboradores reflexiona sobre el punto, avanzando incluso hacia la relación entre las imágenes científicas y la cultura popular y de masas:

Si preguntamos a un taxista 'hágame el dibujo de un psicólogo' te va a hacer un tipo con una libretita y un diván al lado, nunca te va a hacer alguien en un laboratorio haciendo experimentos. Y eso está reforzado en el Río de la Plata; también hay una influencia francesa; y además lo que toma Woody Allen en sus películas. Me encanta Woody Allen pero la verdad que le hace mucho mal a la imagen de la profesión (Entrevista 1).

A partir de nuestro trabajo con las visualidades y de las entrevistas con los colaboradores, mantenemos la tarea permanente de accionar contra la división disciplinar que excluye sensibilidades, afectos, estéticas y conceptos. Por esto es 
importante armar una meta-mirada, una acción analítica y crítica sobre nuestras propias miradas y las de los otros.

\section{Conclusiones}

En este texto he intentado centrar la atención en las visualidades de la ciencia, en términos de cómo los investigadores producen imágenes y las divulgan. Investigar desde la perspectiva de la Cultura Visual me ha llevado a interesarme también por el valor de estas imágenes que emergen de los estudios, los laboratorios, los experimentos de lo que comúnmente definiríamos como el campo de la ciencia.

En el camino recorrido, parece verificarse la proximidad de las ideas de verdad y belleza en el juicio de valor de las imágenes visuales. $Y$, aunque sabemos que esas ideas son contingentes a cada época y contexto, tanto en la ciencia como en el arte, lo cierto es que construyen una relación asociada estrechamente a la actividad científica y a sus visualidades.

En consecuencia, podríamos afirmar que estas imágenes visuales contribuyen a la construcción del mundo real tanto como de la naturaleza de lo humano, en tanto tienen la fuerza y legitimidad que les otorga el respaldo de la evidencia científica y experimental.

Partimos de la idea de que la división de las disciplinas produce también una división sensible respecto de las visualidades. Además, es en la necesidad de tomar opciones tempranas hacia un interés de formación e investigación donde tal régimen disciplinar acaba reforzando su propia condición.

La oportunidad de desarrollo de una política que transforme estas condiciones generales de división disciplinar y sensible podría fundarse, en el campo de estudios abordado, en las siguientes características:

- El lugar y la atracción que tienen las actividades científicas referidas a la actividad cerebral y su lugar en los medios masivos, en la vida cotidiana, y en la representación de la condición humana.

- La posibilidad de la participación en procedimientos experimentales y de divulgación que amplían el espacio del laboratorio científico tradicional y

Revista Digital do LAV - Santa Maria - vol. 11, n. 1, p. 4 - 30 - jan./abr. 2018 ISSN 1983 - 7348 
cruzan fronteras hacia espacios cotidianos de las personas y hacia las disciplinas humanas y artísticas.

- La atracción hacia nuevas formas de representación visual que consideren formas contemporáneas de producción cultural (hemos mencionado la referencia a la idea de misterio), y en donde opere un reconocimiento de las disciplinas científicas como parte de tales prácticas.

Es para mi evidente que el lugar de las imágenes -y lo que se espera de ellascuando se trata de producciones artísticas, es negado para las creaciones científicas. Por esto, confiamos en que aproximaciones como las que realizamos en estos estudios puedan, además de describir el fenómeno, sentar las bases de una alteración política de las actuales delimitaciones de la ciencia y el arte.

\section{Bibliografía}

ANKER, Suzanne; Talasek, J.D. (Eds). Visual Culture and Bioscience. Baltimore: Center of Art, Design, and Visual Culture/University of Maryland-CPNAS, 2008.

FRAZZETTO, Giovanni; ANKER, Suzanne. Neuroculture. In: Nature, Volume 10, November, 2009, 815-821.

GAROIAN, Charles. The Prosthetic Pedagogy of Art. Embodied Research an Practice New York: State University of New York Press, 2013.

; Gaudelius, Yvonne, M. Spectacle Pedagogy. Art, Politics, and Visual Culture, 2008.

RANCIÈRE, Jacques. Sobre políticas estéticas Barcelona: MACBA, 2005.

- El desacuerdo. Política y Filosofía. Buenos Aires: Nueva Visón, 1996.

REICHLE, Ingeborg. Images in Art and Science and the Quest for a New Image Science. In: Leonardo, Volume 48, Number 1, 2015, pp. 74-75.

The Art of DNA. In: Dawn Leach, Slavko Kacunko (Org.) ImageProblem. Medienkunst und Performance im Kontext der Bilddiskussion, Logos

Revista Digital do LAV - Santa Maria - vol. 11, n. 1, p. 4 - 30 - jan./abr. 2018 ISSN 1983 - 7348 
Verlag Berlin 2007, p. 155-166.

Where Art and Science Meet. Genetic Engineering in

Contemporary Art In: kunst-texte.de, BildWissenTechnik, No 2, 2003.

SCHWAN, Alexander Body-Calligraphies: Dance as an Embodied Fantasy of Writing. In: Anker, Suzanne; Flach, Sabine (Eds.) Embodied Fantasies: From Awe to Artifice. Bern: Peter Lang, 2013, pp. 217-227.

i Formación: Doctor en Bellas Artes - Educación Artística / Universidad de Barcelona (España). Afiliación institucional: Profesor Titular Instituto "Escuela Nacional de Bellas Artes" (asimilado a Facultad) / Universidad de la República (Uruguay)

Como citar esse artigo:

MIRANDA, Fernando. Visualidades cruzadas. Un caso de indagación sobre las imágenes de la ciencia experimental. Revista Digital do LAV, Santa Maria: UFSM, v. 11, n. 1, p. 4-30, jan./abr. 2018.

Enviado em: 7 de janeiro de 2018.

Aprovado em: 18 de março de 2018. 